\title{
Radiation Proctitis- Experience at a Tertiary Care Centre of North India
}

\author{
Vani Malhotra, Parveen Malhotra*, Naveen Malhotra, Isha Pahuja, Smiti Nanda, Meenakshi Chauhan, Vandana \\ Bhuriya
}

Department of Gynaecology \& Obstetrics and Medical Gastroenterology, PGIMS, India

*Corresponding author: Parveen Malhotra, Department of Gynaecology \& Obstetrics and Medical Gastroenterology, Anesthesiology, PGIMS, 128/19, Civil Hospital Road, Rohtak, Haryana, India (124001)

Submission: 監 February 20, 2018; Published: 眥 April 03, 2018

\begin{abstract}
Introduction: Proctitis is a troublesome complication in patients receiving radiotherapy in pelvic malignancies. This is a prospective study done to evaluate the efficacy of $4 \%$ formalin in treatment of radiation proctitis and complications associated with it.

Method: Patients with rectal bleeding post radiotherapy for gynaecological malignancy were analysed in our institution from June 2010 -May 2011. $50 \mathrm{ml}$ of $4 \%$ formalin was sprayed through colonoscopy with mucosal contact time of 10 min and observed for $4 \mathrm{hrs}$ for any complication.

Results: A total of 22 patients with mean age 57 (range 40-65) years, moderately built with radiation proctitis were subjected to $4 \%$ formalin and followed up for 12 (range 1-36) months. Mean interval between radiotherapy and presenting symptoms was 15 (range 6 -24) months. Cessation of bleeding occurred in $77.27 \%$ cases after mean of 2(range 1-4) cycles of spray with hemoglobin rise of 2gm\% (range 1.1-2.9). 5 patients complained of intense pain relieved with analgesics and one had seizure. There was only one mortality in a patient who got operated for recto-vaginal fistula and expired on 5 th post-operative day due to septicemia.
\end{abstract}

Conclusion: $4 \%$ formalin application is a simple, cost-effective, and well-tolerated method of controlling hemorrhagic radiation proctitis with less complications. It can be effectively used in settings with limited resources.

\section{Introduction}

Today, radiation to the pelvis is an important constituent in the treatment of pelvic malignancies and is administered either as neoadjuvant or adjuvant therapy [1]. Radiation therapy can be administered via external beam radiation or radioactive implants termed brachytherapy. External beam radiation is typically administered by an external photon generator with a variety of sources including gamma rays, electron beams, and X-rays via a four-beam approach which results in significant exposure to surrounding organs [2]. Brachytherapy involves the implantation of radioactive pellets (typically iodine 125) into the target tissue with a gradual release over time. This reduces exposure damage to surrounding tissue based on careful positioning of the implanted pellets and consequently lesser colorectal complications [3]. Incidence of radiation proctitis is likely related to the dose of radiation, area of exposure, method of delivery, and the use of cytoprotective agents. The doses generally delivered to the pelvis vary from 45 to $50 \mathrm{~Gy}$ for adjuvant or neoadjuvant treatment for prostate or anorectal malignancies; up to 90Gy is considered the definite therapy for gynaecological malignancies. Doses above 70Gy cause significant and long standing injury to the surrounding area $[4,5]$. The Radiation Therapy Oncology Group (RTOG) and the European Organization for Research and Treatment of Cancer
(EORTC) individually attempted to classify the degree of radiation proctitis into a graded system of symptoms progressing from no symptoms to fatal complications [6,7] (Table 1). Radiation proctitis can be managed medically or surgically depending on the severity. Low grade can be managed with the use of nonsteroidal anti inflammatory drugs, sucralfate, short chain fatty acids, hyperbaric oxygen and anti oxidants. More severe variety of proctitis may preclude the use of ablative procedures or surgery. Local ablation with formalin is considered to be a safe and effective way to treat radiation proctitis causing significant bleeding. Formalin scleroses and seals fragile neovasculature in radiation damaged tissues to prevent further bleeding through chemical cauterization $[8,9]$. We have conducted a prospective study to evaluate the efficacy of formalin in managing patients of rectal bleeding with radiation proctitis.

\section{Material and Methods}

The present study was conducted at our prime institute, PGIMS, Rohtak from June 2010 to may 2011. Thirty patients of age ranging from 40-65 years with mean age 57 years with symptoms of rectal bleeding, post-radiotherapy for gynecological malignancies were included in this study. Complete Haemogram was done in every 
patient. Mean hemoglobin of $8.7 \%$ (range - 3.5-11gm\%) was noted with microcytic hypo chromic anemia. Platelets and total leukocyte count was normal. Mean interval between radiotherapy and presenting symptoms- 15 months with range of 6 months- 2 years. 8 patients were excluded and 22 patients out of which, 16 patients had carcinoma cervix and only 6 patients had carcinoma endometrium, underwent colonoscopy. $50 \mathrm{ml}$ of $4 \%$ formalin was sprayed through colonoscopy with a contact period of 10 minutes. Patients were observed for 4 hours for any complications and then followed up weekly. If there is no relief after 1 week, repeat session was done.

\section{Table 1}

\begin{tabular}{|c|c|c|}
\hline Grade & Symptoms / Signs & Overall Management \\
\hline 0 & No symptoms & none \\
\hline 1 & $\begin{array}{r}\text { Occasional urgency and occasional pain; superficial ulceration <1 cm2, occult } \\
\text { bleeding, and mild stricture. }\end{array}$ & Outpatient management; no lifestyle adjustments \\
\hline 2 & $\begin{array}{r}\text { Intermittent urgency and intermittent pain; superficial ulceration }>1 \mathrm{~cm} 2, \\
\text { occasional bleeding, and moderate stricture }\end{array}$ & Outpatient management; some lifestyle adjustments \\
\hline 3 & $\begin{array}{r}\text { Persistent urgency and persistent pain; deep ulceration, persistent bleeding, } \\
\text { severe stricture }\end{array}$ & $\begin{array}{c}\text { Possible short hospital admission or minor surgical } \\
\text { intervention; major lifestyle adjustments }\end{array}$ \\
\hline 4 & $\begin{array}{r}\text { Refractory urgency and uncontrollable pain; gross haemorrhage, perforation, } \\
\text { fistula, complete obstruction }\end{array}$ & $\begin{array}{c}\text { Long-term hospital admission or major surgical intervention } \\
\text { Sepsis, multiorgan failure, and death }\end{array}$ \\
\hline 5 & Fatal complications
\end{tabular}

\section{Observation}

After formalin spray, out of 22 patients, rectal bleeding stopped in 17 patients $(77.2 \%)$ with mean hemoglobin rise of $2 \mathrm{gm} \%$. Patients required 1-4 cycles of spray with mean of 2 cycles. 5 patients remained refractory even after 4 cycles and were treated with argon plasma coagulation. 5 patients required blood transfusion with mean of 3 units (range 1-5 units). 5 patients had intense pain relieved after injectable pain killers. Only 1 patient had seizure. There was only 1 death due to septicemia in a patient operated for recto vaginal fistula.

\section{Discussion}

In radiation proctitis, vascular telangiectasia and nonhealing mucosal ulceration, perhaps due to an underlying obliterative arteritis, may lead to severe recurrent haemorrhage. These patients can be managed conservatively with anti inflammatory agents, sucralfate, short chain fatty acids, antioxidants, ablation procedures with formalin or argon plasma coagulation and in severe cases may require surgery. Formalin application has been an important method for controlling haemorrhage in patients with proctitis. Formalin scleroses and seals fragile neovasculature in radiation damaged tissues to prevent further bleeding through chemical cauterization [10]. Formalin has been historically used as Intravesical instillation in treatment of radiation cystitis $[11,12]$. This concept was first used by Rubinson et al. in 1986 as a method of treating radiation proctitis in a 71 year old male with severe bleeding [13]. Two methods of formalin application have been described so far, which includes rectal instillation of $4 \%$ formalin solution or direct topical application of a $10 \%$ formalin solution [9]. Topical application is generally applied through rigid proctoscope or directly applying with formalin soaked gauge with contact period of about 2-3 minutes. The perianal skin needs to be protected during the procedure to prevent stricture and skin damage. Rectal instillation of $4 \%$ formalin has been successfully employed for treatment of radiation proctitis.

In 1993, Seow-Choen et al. published the first case series involving eight patients treated for intractable rectal bleeding from radiation proctitis with instillation of 4 percent formalin [14]. The bleeding ceased in all patients; however, one developed a worsening stricture requiring Hegar's dilation. Use of formalin in refractory cases of radiation proctitis has been studied by Scalarides et al. [15] in 16 patients. Bleeding stopped in 12 patients after single application and occurred sporadically in 3 patients. Only 1 patient required 3 applications before bleeding stopped and 4 patients had developed significant anal pain and tenesmus after treatment. In 2003, Parikh et al. [9] described the application of cotton pledget soaked in 4 percent formalin applied to the proctitis through a rigid sigmoid scope or operating anoscope. Of 33 patients, 29 (88 percent) had improved or complete resolution of bleeding after a mean of 3.4 treatments and at a follow-up of 18 months. We have reported a case study of 22 patients of gynaecological malignancy who presented with rectal bleeding post radiation proctitis. $4 \%$ formalin was instilled with a mean contact time for 10 minutes. Out of 22 patients, bleeding stopped in 17 patients $(77.7 \%)$ after a mean of 2 sessions. On follow up, these patients had improved haemoglobin with an average rise of $2 \mathrm{mg} \%$. 5 patients were refractory to the treatment and were treated with argon plasma coagulation. 5 patients had rectal pain which was managed with pain killers and no major complication was reported in our study.

\section{Conclusion}

Radiation proctitis can be a therapeutic challenge, even in the most experienced hands. Majority of patients can be treated with topical modalities, while surgery may offer the only chance of relief from life-threatening symptoms. Treatment with local formalin instillation is simple, safe, inexpensive and well tolerated modality and may be used as first line treatment in a poor resource country. 


\section{References}

1. Denton A, Forbes A, Andreyev J, Maher EJ (2002) Non surgica interventions for late radiation proctitis in patients who have received radical radiotherapy to the pelvis. Cochrane Database Syst Rev 1: CD003455.

2. Terasawa T, Dvorak T, Ip S, Raman G, Lau J, et al. (2009) Systematic review: charged-particle radiation therapy for cancer. Ann Intern Med 151(8): 556-565

3. Shah SA, Cima RR, Benoit E, Breen EL, Bleday R (2004) Recta complications after prostate brachytherapy. Diseases of the Colon and Rectum 47(9): 1487-1492.

4. Coia LR Myerson RJ, Tepper JE (1995) Late effects of radiation therapy on the gastrointestinal tract. Int J Radiat Oncol Biol Phys 31(5): 12131236.

5. Beard CJ, Propert KJ, Rieker PP, Clark JA, Kaplan I, et al. (1997) Complications after treatment with external-beam irradiation in early stage prostate cancer patients: a prospective multiinstitutional outcomes study. J Clin Oncol 15(1): 223-229.

6. Pilepich MV, Krall JM, Sause WT (1987) Correlation of radio therapeutic parameters and treatment related morbidity in carcinoma of the prostate-analysis of RTOG study 75-06. Int J Radiat Oncol Biol Phys 13(3): 351-357.

7. Zelefsky MJ, Fuks Z, Hunt M, Yamada Y, Marion C, et al. (2002) High-dose intensity modulated radiation therapy for prostate cancer: early toxicity and biochemical outcome in 772 patients. Int J Radiat Oncol Biol Phys 53(5): 1111-1116.
8. Haas EM, Bailey HR, Farragher I (2007) Application of 10 percent formalin for the treatment of radiation-induced hemorrhagic proctitis. Dis Colon Rectum 50(2): 213-217.

9. Parikh S, Hughes C, Salvati EP, Eisenstat T, Oliver G, et al. (2003) Treatment of hemorrhagic radiation proctitis with 4 percent formalin. Dis Colon Rectum 46(5): 596-600.

10. Haas EM, Bailey HR, Farragher I (2007) Application of 10 percent formalin for the treatment of radiation-induced hemorrhagic proctitis. Dis Colon Rectum 50(2): 213-217.

11. Shah BC, Albert DJ (1973) Intravesical instillation of formalin for the management of intractable hematuria. J Urol 110(5): 519-520.

12. Shrom SH, Donaldson MH, Duckett JW, Wein AJ (1976) Formalin treatment for intractable hemorrhagic cystitis. Cancer 38(4): 17851789.

13. Rubinstein E, Ibsen T, Rasmussen RB, Reimer E, Sorensen BL (1986) Formalin treatment of radiation-induced hemorrhagic proctitis. Am J Gastroenterol 81(1): 44-45.

14. Seow-Choen F, Goh H, Eu K, Ho Y, Tay S (1993) A simple and effective treatment for hemorrhagic radiation proctitis using formalin. Dis Colon Rectum 36(2): 135-138.

15. Saclarides TJ, King DG, Franklin JL, Doolas A (1996) Formalin instillation for refractory radiation-induced hemorrhagic proctitis: report of 16 patients. Dis Colon Rectum 39(2):196-199.
Creative Commons Attribution 4.0 International License

For possible submissions Click Here

\section{Submit Article}

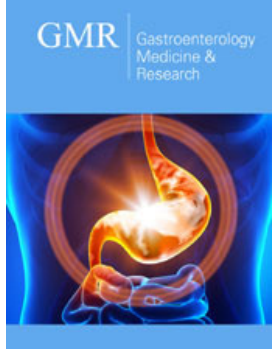

Gastroenterology Medicine \& Research

\section{Benefits of Publishing with us}

- High-level peer review and editorial services

- Freely accessible online immediately upon publication

- Authors retain the copyright to their work

- Licensing it under a Creative Commons license

- Visibility through different online platforms 